\title{
Ablation of idiopathic ventricular tachycardia originating from posterior mitral annulus by using electroanatomical mapping
}

This article was published in the following Dove Press journal:

International Medical Case Reports Journal

4 March 2015

Number of times this article has been viewed

\author{
Tolga Aksu' \\ Tumer Erdem Guler' \\ Ebru Golcuk ${ }^{2}$ \\ Kazım Serhan Ozcan' \\ Ismail Erden' \\ 'Department of Cardiology, Derince \\ Training and Research Hospital, \\ Kocaeli, Turkey; ${ }^{2}$ Department of \\ Cardiology, School of Medicine, Koç \\ University, Istanbul, Turkey
}

\begin{abstract}
Idiopathic ventricular tachycardia (IVT) is an important type of arrhythmia, which has distinct electrocardiographic features and treatment options. Most of the cases originate from right ventricular outflow tract and less frequently from the left ventricular outflow tract. IVTs originating from mitral annulus are rare, and little is known about the efficacy of radiofrequency catheter ablation in this form. We hereby present a rare case of IVT arising from posterior mitral annulus. The electrocardiographic, electrophysiological, and electroanatomical characteristics of this tachycardia are discussed.
\end{abstract}

Keywords: radiofrequency, ventricular arrhythmia

\section{Introduction}

Idiopathic ventricular tachycardias (IVTs) account for $10 \%$ of all ventricular tachycardia (VT) cases. ${ }^{1}$ The majority of IVT originates from the right ventricular outflow tract. Eighty percent of IVT originates from the left ventricular outflow tracts and left ventricular fascicles. ${ }^{2}$ The incidence of VT originating from mitral annulus has been reported as $5 \%{ }^{3}$ Although tachycardia electrocardiogram (ECG) usually shows wide QRS complex, IVTs encountered in patients without structural heart disease are associated with relatively narrow QRS tachycardia. Radiofrequency catheter ablation (RFCA) is considered an important option in the treatment of IVT. We hereby present a case who underwent successful RFCA for IVT originating from posterior mitral annulus.

\section{Case presentation}

A 32 year-old male presented to our emergency department with the complaint of palpitation and dizziness, which started 30 minutes before his arrival at hospital. On physical examination the patient was excessively sweating, his blood pressure was 104/64 $\mathrm{mmHg}$, with a heart rate of 185 beats per minute and respiration rate of 22 breaths per minute. The patient's heart sounds were normal, without murmur. The ECG showed wide QRS tachycardia, suggestive of VT with a morphology of right bundle branch block (RBBB), left superior axis, and negative QRS concordance in precordial leads (Figure 1). Atrioventricular dissociation and fusion beats were also seen on the admission ECG. Clinical tachycardia was terminated by intravenous propafenone at a dose of $2 \mathrm{mg} / \mathrm{kg}$. Although propafenone does not play a role as "first line" drug in this situation, the patient did not give consent to direct current cardioversion. The selection of propafenone as a first antiarrhythmic was the choice of the emergency physician. The physical examination was unremarkable. Transthoracic echocardiography revealed a
Correspondence: Tolga Aksu Department of Cardiology, Derince Training and Research Hospital, 4I500 Kocaeli, Turkey

Tel +905319903278

Fax +902623178000

Email aksutolga@gmail.com (c) (1) (5) 2015 Aksu et al. This work is published by Dove Medical Press Limited, and licensed under Creative Commons Attribution - Non Commercial (unported, v3.0) License. The full terms of the License are available at http://creativecommons.org/licenses/by-nc/3.0/. Non-commercial uses of the work are permitted without any further fom Dove Medical Press Limited, provided the work is properly attributed. Permissions beyond the scope of the License are administered by Dove Medical Press Limited. Information on how to request permission may be found at: http://www.dovepress.com/permissions.php 


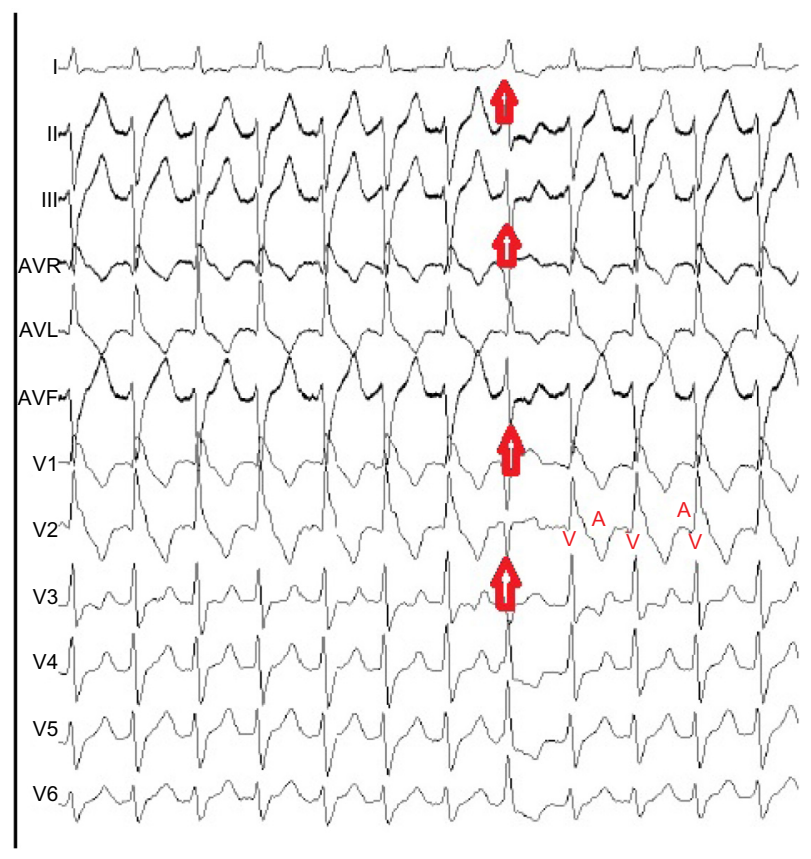

Figure I Surface ECG recording taken during clinical ventricular tachycardia. Note: Right bundle branch block, superior axis, A-V dissociation, and fusion beats (arrow) are seen on ECG.

Abbreviations: A, atria; ECG, electrocardiogram; $V$, ventricles.

normal left ventricular systolic function, with an ejection fraction of $65 \%$ and no structural heart disease.

Regarding his medical history, he had been suffering from multiple episodes of palpitations and presyncope for 2 years; pharmacological therapy by beta blockers (metoprolol $50 \mathrm{mg} /$ daily) or propafenone was ineffective and limited by side effects (fatigue and erectile dysfunction). The patient's symptoms had worsened for 2 months, and the last two tachycardia episodes ended with syncope.

The RBBB pattern and the leftward axis during VT suggested the left ventricle (LV) to be the source of arrhythmia. An electrophysiological study was performed to identify the mechanism of tachycardia and RFCA. With fluoroscopic guidance, a deflectable decapolar catheter (Cordis-Webster, Diamond Bar, CA, USA) was placed in the coronary sinus via the left femoral vein. Quadripolar catheters (Cordis-Webster) were introduced through the right femoral vein and positioned in the His-bundle region and the right ventricular apex.

Although clinical tachycardia was easily reproduced by programmed right ventricular stimulation (Figure 2), entrainment was not seen with overdrive pacing. A $4 \mathrm{~mm}$ multicurve ablation catheter (Marinr ${ }^{\circledR}$; Medtronic Inc., Minneapolis, MN, USA) was applied to the LV via retrograde aortic approach. Left ventricular activation mapping was initially performed by using a three-dimensional electroanatomical mapping system (Ensite NavX ${ }^{\circledR}$; St Jude Medical, Inc., St Paul, MN,

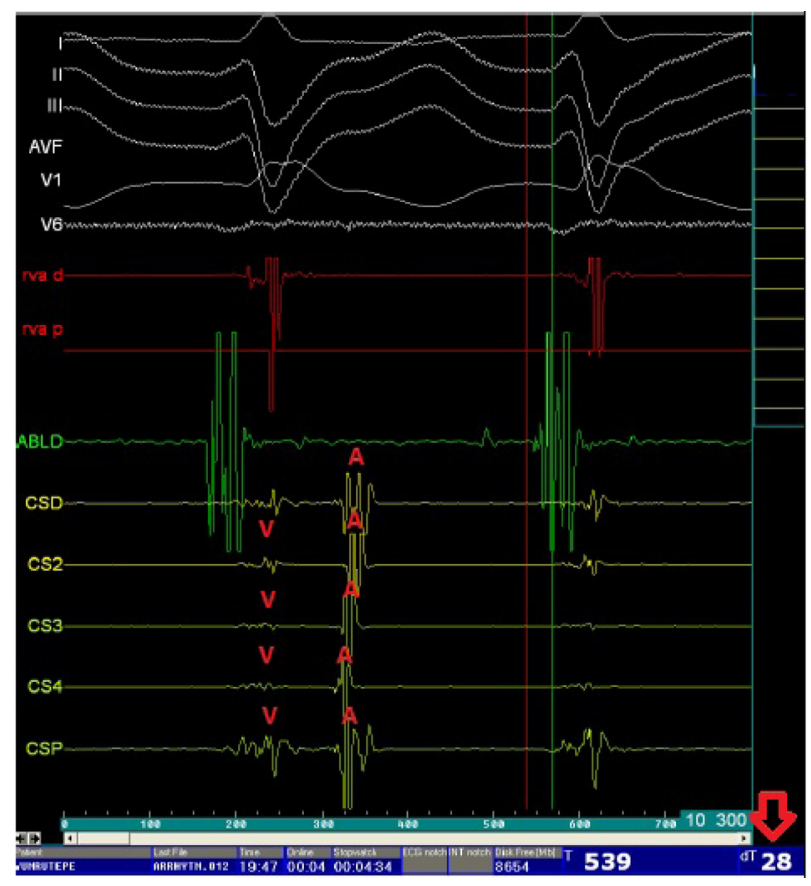

Figure 2 Intracardiac recordings.

Note: During clinical tachycardia, the ventricular potential recorded by the distal ablation catheter (ABLD) preceded the onset of surface QRS complex by $28 \mathrm{~ms}$. Abbreviations: $A$, atrial intracardiac electrogram; $A B L D$, distal ablation electrode; CSD, coronary sinus distal; CSP, coronary sinus proximal; rvad, right ventricle distal; rvap, right ventricle proximal; $\mathrm{V}$, ventricular intracardiac electrogram.

USA). The earliest site of ventricular activation (preceding the onset of the surface QRS by $28 \mathrm{~ms}$ ) was identified at the posterior wall of the LV (Figure 3). Pace-mapping at this location demonstrated a good match (eleven of 12 leads) with the morphology of the VT.

The earliest site of activation which was compatible with VT originating from posterior mitral annulus was considered as the ablation target. The first radiofrequency energy application (target temperature of $60^{\circ} \mathrm{C}, 50 \mathrm{~W}, 60$ seconds) abolished VT (Figure 4). Additional radiofrequency applications were delivered at this region in order to ensure long-term success. Programmed right ventricular stimulation, with and without isoproterenol, failed to induce the tachycardia. One year after the procedure, the patient is free from any arrhythmias.

\section{Discussion}

In this paper, we described a rare form of IVT. Detailed analysis of clinical tachycardia ECG shows negative QRS polarity in the inferior leads, deep $\mathrm{S}$ wave in V6, positive QRS complex in V1, and late notching of the $\mathrm{R}$ wave in the inferior leads was suggestive of VT originating from the posterior mitral annulus.

IVTs are classified with respect to the ventricle of origin, the response to pharmacologic agents, evidence of 


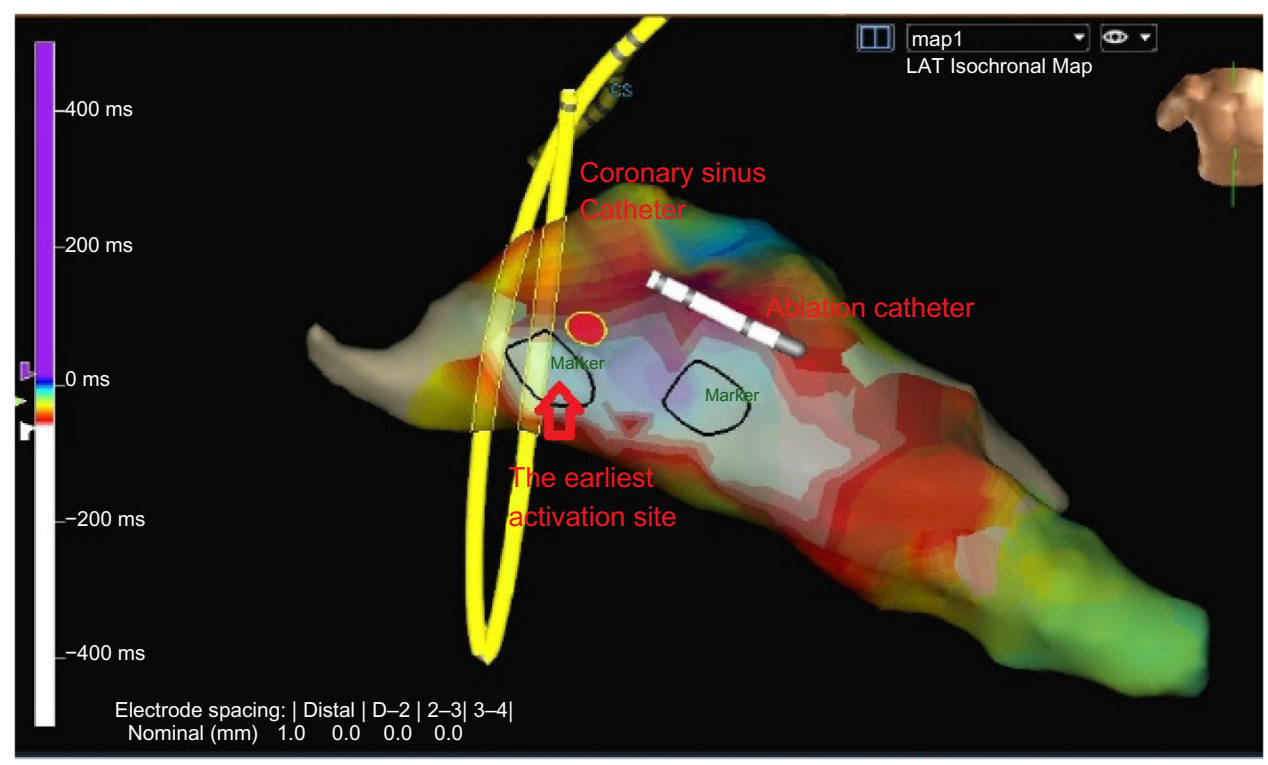

Figure 3 Electroanatomic activation map of the left ventricle for clinical ventricular tachycardia, with the earliest activation and ablation site at the posterior mitral annulus (left anterior oblique view).

Notes: The isochronal activation map was constructed during tachycardia using proximal coronary sinus ventricular signal as a reference point. The color-coded display of the activation time in the left ventricle measured relative to the reference point. White color and blue color indicate the earliest and the latest activated sites, respectively. The activation map shows a very early target (white) in the posterior mitral annular area. Yellow and white catheters are coronary sinus catheter and the ablation catheter, respectively. The two circled areas indicate the best option for ablation.

catecholamine dependence, and the specific morphologic features. Most IVTs or premature ventricular contractions (PVCs) have a right ventricular or left ventricular outflow tract origin, ${ }^{4,5}$ but some originate from the anterolateral portion of the mitral annulus in close proximity to the mitralaortic continuity. ${ }^{6,7}$
Tada et $\mathrm{al}^{3}$ reported that $5 \%$ of IVT/PVCs originate from the mitral annulus. They studied the prevalence, ECG characteristics, and preferential site of tachycardia origin within the mitral annulus and the efficacy of RFCA for IVT of this kind. They revealed that mitral annular VTs may be divided into three distinct groups: anterolateral, posteroseptal, and

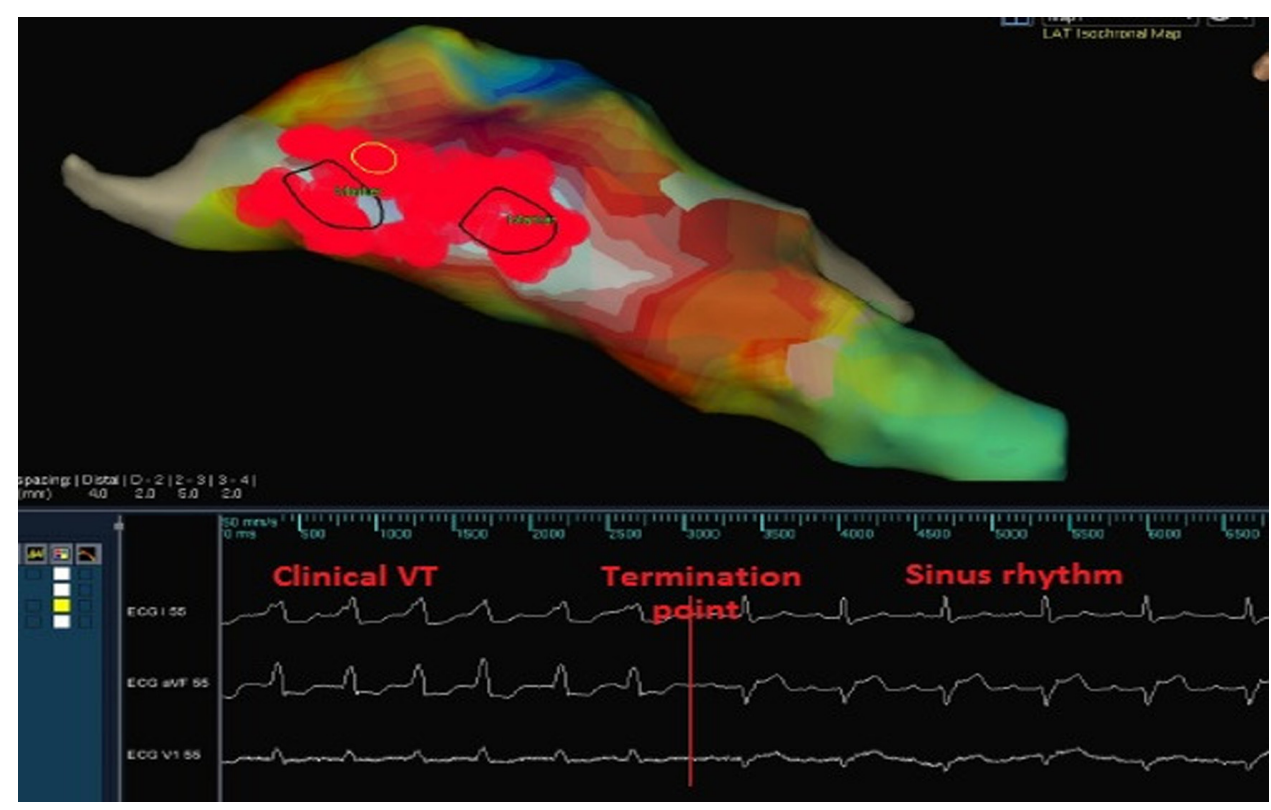

Figure 4 Three-dimension electroanatomical mapping of the left ventricle.

Notes: Red dots indicate ablation lesions; After radiofrequency application, the termination of clinical tachycardia is seen on surface electrogram at the bottom of the figure. The two circled areas indicate the best option for ablation.

Abbreviation: VT, ventricular tachycardia. 
posterior. They demonstrated that the anterolateral annulus was the most common site to host arrhythmogenic foci around the mitral annulus. ${ }^{3}$

To identify the precise tachycardia origin at the mitral annulus, several characteristic ECG findings were suggested at the end of detailed ECG analysis. As shown in our case, RBBB configuration on ECG was typical for mitral annular VT. V2-V4 derivations may have monophasic R or RS complexes may be detected in V2-V4 precordial derivations. ${ }^{8}$ Polarity of the QRS complex in the inferior leads and leads I and aVL was useful for differentiating anterolateral form from posterior and posteroseptal forms. The presence of a negative component in the QRS complex in leads I and V1 or a greater Q-wave amplitude ratio of lead III to lead II was useful for differentiating posteroseptal-mitral annular VT from posterior-mitral annular VT. The notching in late phases of QRS complexes in inferior leads was useful for differentiating anterolateral and posterior-mitral annular VT from posteroseptal-mitral annular VT.

The QRS morphology in our patient was similar to those reported by Tada et $\mathrm{al}^{3}$ for posterior-mitral annular VT/ PVCs. In their series, among the $19 \mathrm{VT} / \mathrm{PVCs}$ originating from the annulus, two originated from the posterior mitral annulus. However, in contrast to our case, these patients did not demonstrate sustained VTs but only isolated PVCs from the region of the mitral annulus.

Focal reentry appears to be the principal mechanism of IVT. Programmed stimulation may induce tachycardia, but entrainment is not seen with overdrive pacing. Some authors have suggested triggered afterdepolarization as the operative mechanism of the tachycardia. ${ }^{9,10}$ Belhassen type IVT is inducible and terminable by programmed stimulation and can be entrained by overdrive ventricular pacing. ${ }^{11}$ Whereas, abnormal automaticity in different sites of the LV has been implicated as a potential source of IVT originating from mitral annulus. In a previous study, the Purkinje fibers of the fascicle are speculated to be the area of slow conduction because of the presence of high-frequency potentials (Purkinje potentials). ${ }^{12}$ Late diastolic potentials near the main trunk of the left bundle branch are investigated as another potential source. Another hypothesis implicates a false tendon extending from the inferoposterior aspect of the LV to the basal septum as directly or indirectly having a role in causing this arrhythmia. ${ }^{13}$

Some sites are suggested as foci of IVT originating from the LV. The close proximity of the anterolateral portion of the mitral annulus to the anterior attachment of the right ventricular outflow, the LV epicardial myocardium to the left sinus of Valsalva, and the anteromedial (subvalvular) portion of the LV outflow tract suggests that these different forms of IVT could likely originate from a single focus, with different exit points or activation of alternative pathways between the tachycardia focus and an exit point. ${ }^{14}$

Due to focal origin of VT, the most important step for the successful ablation of IVT originating from mitral annulus is the detection of optimal earliest activation site. More recently, with the widespread use of electroanatomical mapping systems, the use of pace-mapping has declined and the duration of ablation has decreased. In our case, the earliest activation site was detected in the posterior mitral annulus by electroanatomical mapping, and focal ablation of this site successfully terminated the tachycardia.

\section{Conclusion}

VT originating from mitral annulus is a rare form of IVT and can be partially diagnosed with ECG. RFCA is the preferred treatment option in these cases although the success rate is lower than for other IVT forms.

\section{Disclosure}

There was no financial support for this study. The authors report no conflicts of interest in this work.

\section{References}

1. Belhassen B, Viskin S. Idiopathic ventricular tachycardia and fibrillation. J Cardiovasc Electrophysiol. 1993;4(3):356-368.

2. Brooks R, Burgess JH. Idiopathic ventricular tachycardia. A review. Medicine (Baltimore). 1988;67(5):271-294.

3. Tada $\mathrm{H}$, Ito $\mathrm{S}$, Naito $\mathrm{S}$, et al. Idiopathic ventricular arrhythmia arising from the mitral annulus: a distinct subgroup of idiopathic ventricular arrhythmias. J Am Coll Cardiol. 2005;45(6):877-886.

4. Coggins DL, Lee RJ, Sweeney J, et al. Radiofrequency catheter ablation as a cure for idiopathic tachycardia of both left and right ventricular origin. J Am Coll Cardiol. 1994;23(6):1333-1341.

5. Daoud E, Morady F. Catheter ablation of ventricular tachycardia. Curr Opin Cardiol. 1995;10(1):21-25.

6. Yeh SJ, Wen MS, Wang CC, Lin FC, Wu D. Adenosine-sensitive ventricular tachycardia from the anterobasal left ventricle. $J$ Am Coll Cardiol. 1997;30(5):1339-1345.

7. Kondo K, Watanabe I, Kojima T, et al. Radiofrequency catheter ablation of ventricular tachycardia from the anterobasal left ventricle. Jpn Heart J. 2000;41(2):215-225.

8. Kumagai K, Yamauchi Y, Takahashi A, et al. Idiopathic left ventricular tachycardia originating from the mitral annulus. J Cardiovasc Electrophysiol. 2005;16(10):1029-1036.

9. Wu D, Kou HC, Hung JS. Exercise-triggered paroxysmal ventricular tachycardia. A repetitive rhythmic activity possibly related to afterdepolarization. Ann Intern Med. 1981;95(4):410-414.

10. Lerman BB, Belardinelli L, West GA, Berne RM, DiMarco JP. Adenosine-sensitive ventricular tachycardia: evidence suggesting cyclic AMP-mediated triggered activity. Circulation. 1986;74(2): 270-280.

11. Belhassen B, Rotmensch HH, Laniado S. Response of recurrent sustained ventricular tachycardia to verapamil. Br Heart J. 1981;46(6): 679-682. 
12. Nakagawa H, Beckman KJ, McClelland JH, et al. Radiofrequency catheter ablation of idiopathic left ventricular tachycardia guided by a Purkinje potential. Circulation. 1993;88(6):2607-2617.

13. Thakur RK, Klein GJ, Sivaram CA, et al. Anatomic substrate for idiopathic left ventricular tachycardia. Circulation. 1996;93(3):497-501.
14. Kimber SK, Downar E, Harris L, et al. Mechanisms of spontaneous shift of surface electrocardiographic configuration during ventricular tachycardia. J Am Coll Cardiol. 1992;20(6):1397-1404.

International Medical Case Reports Journal

\section{Publish your work in this journal}

The International Medical Case Reports Journal is an international, peer-reviewed open-access journal publishing original case reports from all medical specialties. Previously unpublished medical posters are also accepted relating to any area of clinical or preclinical science. Submissions should not normally exceed 2,000 words or
4 published pages including figures, diagrams and references. The manuscript management system is completely online and includes a very quick and fair peer-review system, which is all easy to use. Visit http://www.dovepress.com/testimonials.php to read real quotes from published authors.

Submit your manuscript here: http://www.dovepress.com/international-medical-case-reports-journal-journal 